\title{
A PAISAGEM NO TEATRO DE GERTRUDE STEIN E SEUS DESDOBRAMENTOS
}

\section{THE LANDSCAPE IN GETRUDE STEIN'S THEATRE AND ITS UNFOLDINGS}

\section{Dirce Waltrick do Amarante ${ }^{1}$}

RESUMO: No final do século XIX, o teatro passou por uma revolução cênica na Europa. No século XX, a escritora e dramaturga norte-americana Gertrude Stein, radicada em Paris, levou adiante essas transformações, propondo "peças-paisagem", as quais mesclam teatro com artes plásticas, impondo uma nova forma de percepção teatral.

PALAVRAS-CHAVE: Teatro. Gertrude Stein. Vanguarda.

ABSTRACT: At the end of the 19th century, European theater underwent a scenic revolution. In the 20th century, the American author and playwright Gertrude Stein, who had settled in Paris, took these transformations to the next level by proposing "Landscape Theatre", a convergence of theater with visual arts, thus imposing a new form of theatrical perception.

KEYWORDS: Theatre. Gertrude Stein. Avant-Garde.

\footnotetext{
${ }^{1}$ Doutora (20060 e Mestre (2001) em Literatura pela Universidade Federal de Santa Catarina. Graduada em Direito (1991) pela mesma universidade. Professora Adjunta IV no Curso de Artes Cênicas e no Programa de Pós-Graduação em Estudos da Tradução ambos da Universidade Federal de Santa Catarina. Florianópolis, Santa Catarina, Brasil. E-mail: waltrickdoamarantedirce@gmail.com
} 
No final do século XIX, os simbolistas se mostraram fatigados com o teatro naturalista, que seria o "falso por definição" (HUBERT, 2013, p. 229), como afirmou Édouard Émile Dujardin. Para os simbolistas a atmosfera do drama deveria surgir da poeticidade do texto, como pregava o ensaio "Da inutilidade absoluta da encenação exata", de 1891, escrito pelo poeta e ensaísta Pierre Quillard: "A palavra cria o cenário, assim como todo o resto" (Ibidem). A intensão dos simbolistas era não só suprimir todo o cenário construído realisticamente, como também suprimir a presença física dos atores, "homens necessariamente disformes, incapazes de fazer o público admitir que são os deuses que macaqueiam" (Ibidem), como alertava Dujardin.

O poeta Stéphane Mallarmé, autor de uma peça inacabada, Herodíade, também sonhava com um teatro sem personagem e sem ação. Mallarmé dizia preferir a leitura ao espetáculo. A partir das ideias simbolistas, Alfred Jarry (1873-1907), um jovem francês excêntrico, dá uma verdadeira guinada nas concepções teatrais e funda, como afirmam os estudiosos, a estética moderna.

No texto "Da inutilidade do teatro no teatro", Jarry (1962) defende, assim como defendiam os simbolistas, que o teatro não deveria oferecer qualquer espécie de ilusão da realidade. Além disso, seu texto defendia o artifício na criação da personagem, liberando os artistas da pretensão de recriação de um ser humano real (HUBERT, 2013, p. 22). Na estreia de Ubu rei, a vaia teria sido geral se não fosse por uns poucos presentes, como Mallarmé, que afirmou: "Jarry é poeta e com este Ubu rei começa uma nova época". Embora tenha sido uma frase profética, ela ficou incompreendida por muito tempo. 
Os movimentos artísticos do século XX, no entanto, começaram a dar valor a Jarry. O movimento dadaísta, que nasceu na Suíça em 1916, se identificou com a sua estética e foi influenciado por ela. Mas, tanto as obras dadaístas quanto o Ubu rei foram vistos, na época, apenas como "infantilismo agressivo", ainda que desse "infantilismo" brotasse um protesto sério contra a violência e a corrupção. Ubu é um tirano, um ditador cruel e estúpido como muitos ditadores o foram e o são ao longo da história. Mais tarde, os surrealistas também se identificaram com $U b u$ rei e suas frases que oscilam entre o real e o irreal, entre o humor-negro e a mística do absurdo.

A peça de Jarry se estrutura sobre uma dramaturgia alógica, que põe em xeque as leis do dia a dia e a ilusão de um pensamento lógico e linear. Diria que Alfred Jarry profanou o teatro e o devolveu, no final do século XIX, ao uso comum dos homens. Com isso, fez o teatro progredir e ganhar um novo status e novas experimentações estéticas. De tempos em tempos, o teatro necessita de um novo Jarry que ponha o teatro abaixo para que então ele seja reconstruído.

Esse é o caso da escritora norte-americana Gertrude Stein (1874 -1946), que escreveu suas peças consideradas há época, e talvez ainda hoje, impossíveis de levar ao palco, uma vez que nelas não existem rubricas, quase não se encontra indicação de personagens nem pistas que auxiliem a sua encenação e também não existe uma história, uma fábula a ser contada.

Na opinião de Stein, uma peça não deveria contar uma história, como fazia o romance e se o teatro estava falhando no século dezenove é porque tentava colocar seus romances no palco. Lembra Hans-Thies Lehmann que a dramaturga costumava dizer que "quando ia ao teatro se punha sempre muito nervosa, porque tinha que lembrar e ansiar por algo, e ela não queria isso" (LEHMANN, 2009, p. 246). Ela queria simplesmente estar lá, sem se preocupar em acompanhar um enredo. Para ela, aliás, "quanto melhor a peça, mais estática" ela deveria ser (RYAN, 2006, p. 41).

Para atingir esse grau de imobilidade em seus textos, Stein se vale do presente contínuo, que impede a progressão temporal. Além disso, a dramaturga procura recriar "a essência do que aconteceu" e a essência do objeto, outro recurso que não leva em consideração o avançar do tempo nem o desenrolar de um enredo como se lê, por exemplo, na peça $O$ que aconteceu (1913): "Um tigre um sobretudo enlevado e cercado seguramente planejado com manchas velho o bastante para ser julgado útil e espirituoso num segredo e numa agitação ofuscante" (AMARANTE; COLLIN, 2014, p. 25).

Nas peças de Stein, nem mesmo os diálogos, isolados uns dos outros, levam a algum lugar. Numa entrevista, Gertrude Stein explicou da seguinte maneira a composição de suas peças: "eu costumo pegar um objeto da mesa, como um copo ou qualquer espécie de objeto, e tento captar a imagem disso de modo claro e distinto em minha mente e criar uma relação de palavra entre as palavras e as coisas vistas" (PERLOFF, 2008, p. 123). Segundo a dramaturga, "qualquer coisa que possa contar uma história pode ser uma peça e por outro lado 'quando eu vejo uma coisa, isso não é uma peça para mim, mas quando eu 
escrevo alguma coisa que alguém pode ver, então isso é uma peça para mim" (STEIN, 1975, p. VIII).

A dramaturga dizia que nada como uma paisagem para se criar a partir dela uma peça teatral diante dessa afirmação, passou a chamar suas peças de peçaspaisagem.

Em 1935, Gertrude Stein explicou que as peças teatrais de Opera and plays são paisagens e foram inspiradas pela paisagem ao redor de sua casa de verão em Bilignin, na França. Mas ninguém deve esperar encontrar a região francesa em suas peças num sentido de lugar. Na opinião da estudiosa Jane Palatin Bowers, "quando Stein chama as suas peças de paisagens, ela está esboçando uma analogia com um gênero da arte - as pinturas de paisagem. Imaginando suas peças como pinturas de paisagem, Stein estava livre das convenções dramáticas e livre para experimentar novas formas" (2002, p. 121).

Convém lembrar ainda que Stein tinha grande contato com os pintores de vanguarda, seus contemporâneos. Ela conhecia inúmeros deles, expunha seus trabalhos e opinava a respeito de sua estética. Em Lectures in America, Gertrude Stein teria afirmado o seguinte:

como eu disse, todo mundo tem que gostar de alguma coisa; algumas pessoas gostam de comer, outras gostam de beber; algumas gostam de fazer dinheiro, outras gostam de gastar dinheiro; algumas gostam de teatro... e eu, pessoalmente, gosto bastante de todas essas coisas, mas elas não prendem a minha atenção por muito tempo. A única coisa, bem divertida, que eu nunca fico cansada de fazer é olhar um quadro. (RYAN, 2006, p. 34)

A estética de Paul Cézanne (1839-1906) teria influenciado fortemente a escrita de Stein, sobretudo a das peças-paisagem. Cézanne, como se sabe, pintava elementos estáticos. Segundo Will Gompertz, Cézanne escolhia "uma combinação de temas estáticos: construções da fazenda, gamela de água, feno. Isso porque ele preferia pintar entidades que não se moviam: motivos para os quais pudesse olhar longamente, que lhe proporcionassem a oportunidade de desenvolver uma reflexão apropriada sobre o que estava vendo" (GOMPERTZ, 2012, p. 98).

Stein, como Cézanne, combinava uma série de olhares sobre um tema/objeto e assim aumentava a informação visual oferecida. A escritora parece compartilhar ainda a ideia de visão binocular de Cézanne e, por isso, ela representa sempre um tema visto de dois ângulos diferentes.

Outras peças de Stein, que eu chamaria de paisagens abstratas, incorporaram a estética de pintores pós-Cézanne, em que a forma se sobrepõe ao tema, e por isso a dificuldade em compreendê-las num primeiro "olhar" é maior.

$\mathrm{O}$ contato com pintores do início do século XX também exerceu grande influência na escritura da autora, então residindo em Paris. Não é difícil ver na escrita de Stein traços de Paul Cézanne, Pablo Picasso e Henri Matisse. Stein dizia que "Cézanne descobriu a graça de deixar coisas inacabadas e distorcidas por uma questão de necessidade; com Matisse aconteceu o mesmo, mas foi 
deliberado" (STEIN, 2006, p. 45). Na peça Ao país totalmente, de Gertrude Stein, lemos a descrição fragmentária e distorcida de uma cidade que não tem centro ora, como não pensar numa paisagem de Cézanne ou de Matisse: "Uma avenida passa por uma cidade e uma rua a atravessa atravessa a cidade. Não há nenhum sentido em apontar associações. Muitas pessoas sabem ler. Não mulheres. Não em alguns países. Não em alguns países. Ah sim não em alguns países" (AMARANTE; COLLIN, 2014, p. 62).

De todos os pintores modernos, Picasso talvez tenha sido aquele que mais influenciou Gertrude Stein. Segundo ela, as pinturas cubistas de Picasso eram "tão estranhas que a primeira coisa que se fazia, instintivamente, em vez de olhar logo para elas, era concentrar-se em qualquer ponto" (STEIN, 2006, p. 13).

Fato é que os textos teatrais de Stein estariam muito próximos do teatro pós-dramático que, como afirma o estudioso alemão Hans-Thies Lehmann, "não é isto, não é aquilo e nem é outra coisa: predomina a ausência de categorias e palavras para a determinação positiva e a descrição daquilo que ele é" (2007, p. 22).

Segundo a crítica especializada, os textos dramáticos de Stein não teriam alcançado "êxito" no palco, o que não significa que a escritora seja um evidente fracasso como autora teatral. Ao contrário, esclarece Lehmann, se suas peças são consideradas impossíveis dentro e fora do palco é porque seus textos são avaliados de acordo com a perspectiva do teatro dramático, o qual não percebe que as formas textuais de Stein já anunciem o fim da tradição desse teatro (2007, p. $80-81)$.

Para Lehmann, Stein seria incontestavelmente uma das precursoras, e talvez até mesmo um modelo, do chamado "teatro pós-dramático". Segundo o estudioso alemão, existe uma forte relação desse teatro

com aqueles movimentos de vanguarda [dos quais Stein fazia parte] que, proclamando o desmantelamento do contexto, o privilégio da falta de sentido e da ação no aqui e agora (dadaísmo), abandonaram o teatro como 'obra' e produção de sentido em nome de um impulso agressivo, de um acontecimento que incluía o público em ações (futurismo) ou sacrificava o nexo causal narrativo em favor de outros ritmos de representação, em especial a lógica do sonho (surrealismo). (2007, p. 99)

O teatro de Gertrude Stein assemelha-se também ao teatro de risco: "arriscado, porque rompe com muitas convenções. Os textos não correspondem às expectativas com as quais as pessoas costumam encarar textos dramáticos. Muitas vezes é difícil até mesmo descobrir um sentido, um significado coerente da representação" (LEHMANN, 2005, p. 38. Grifo do autor).

O fato é que nos textos teatrais da escritora americana não há nenhuma ação óbvia, nenhuma história facilmente discernível. As palavras, os gestos e o sentido são fragmentários (uma das características, aliás, do texto moderno).

Inserida na modernidade e assumindo um padrão de escritura vanguardista, cuja linguagem transgressiva foi praticada grosso modo até o final dos anos 1930 (KRYSINSKI, 2007, p. 19), Gertrude Stein questionou nas suas criações radicais 
a concepção tradicional de peça teatral. Sua concepção de texto dramático diferia da concepção da grande maioria dos dramaturgos da época, cujos trabalhos visavam o palco ou o papel impresso.

A escritora norte-americana estava ciente de que a obra que um autor imagina e aquela que o público, o ator e o diretor imaginam são dois fenômenos diferentes (KRYSINSKI, 2007, p. VIII). O ator, na montagem de suas peças, pode agir como um performer, reformulando sua atuação a cada nova apresentação, uma vez que nada está programado para ele.

O papel do espectador também é central no teatro de Stein, que, como afirma Penny Farfan, "ela considerava menos sobre representação do que sobre experiência". (2010, p. 55. Tradução nossa). A propósito, o pintor Henri Matisse dizia que o mundo para Gertrude Stein era um teatro. Stein transformava cenas cotidianas em grandes perfomances, como fez certa vez numa exposição em Paris, quando a escritora colocou cada pintor diante de seu quadro "quase como um jogo ou uma performance teatral", e assistiu à reação de seus convidados (STEIN, 2006, p. 19).

Stein compôs uma obra teatral feita de descontinuidades, de dissolução da narração, de privação da fala e de suspensão do sentido. Um teatro sem personagem, onde ressoam vozes, como lemos em "Vozes de mulheres":

Vozes de mulheres dão prazer.

O segundo ato é fácil de dirigir. Direção não é no

inverno. Aqui o inverno é ensolarado.

Isso surpreende você.

Vozes de mulheres juntas e então ela entrou.

Muito bem boa noite.

Muito bem boa noite.

(Sra. Cardillac)

Isso é prata.

Você se refere ao som.

Sim ao som.

(AMARANTE; COLLIN, 2014, p. 47)

As peças de Stein são também repletas de condensações, de repetições e do aproveitamento casual de qualquer coisa que estivesse à sua volta (STEIN, 1975, p. VIII).

De acordo com Carl Van Vechten, o escritor americano Thornton Wilder acreditava que parte da arbitrariedade do texto de Stein - "Ato I e Ato III etc." - é seu golpe satírico ao pedantismo e ao formalismo em geral, sua maneira de dizer "não me limitem" (STEIN, 1975, p. VIII). Mas Stein estava dentro de uma tradição de escritores vanguardistas que, como lembra Wladimir Krysinski,

proclamam sua diferença e operam a ruptura. Cada vez que isso se produz, treme $\mathrm{o}$ edifício da arte $\mathrm{e}$ da literatura. Presumivelmente. Pelo menos, os vanguardistas estimam-se suficientemente revolucionários e destruidores para que a arte e a literatura não sejam mais as mesmas na sequência de suas artimanhas ostentatórias. (2007, p. 22) 
Segundo Carl Van Vechten, Gertrude Stein trabalhava com a similaridade na busca de uma unidade para os seus primeiros textos teatrais; por isso mesmo, eles podem ser lidos como uma obra única ligada pela homogeneidade de seu método. Além disso, mais do que uma trama, Stein estava preocupada com "frases, não só palavras, mas frases e mais frases", que dão ritmo característico ao desenvolvimento de seus textos teatrais (STEIN, 2006, p. 45). Em "Capitão Walter Arnold", lemos:

Você consegue se lembrar de algum exemplo de repetição fácil. Posso e posso mencioná-la. Posso explicar como em duas repetições você muda o significado você verdadeiramente muda o significado. Isso o faz mais interessante. Se o vinculamos a uma pessoa nos voltamos a uma compreensão.

Diante do estranhamento que provoca a leitura das peças de Stein, desviar o olhar parece ser a primeira reação do leitor iniciante. Persistir na leitura de seus textos poderá revelar, no entanto, uma paisagem sob a névoa encantadoramente misteriosa.

\section{REFERÊNCIAS}

AMARANTE, Dirce Waltrick do; COLLIN, Luci (Org.). O que você está olhando. São Paulo: Iluminuras, 2014.

BOWERS, Jane Palatini. The composition that all the world can see: Gertrude Stein's theater landscapes. IN: FUCHS, Elinor; Chaudhuri, Una (Org.). Land/Scape/Theatre. Ann Arbor: Universty of Michigan, 2002.

FARFAN, Penny. Women`s modernism and performance. In: LINETT, Maren Tova (Org.). Modernist women writers. Cambridge: Cambridge University Press, 2010.

GOMPERTZ, Will. Isso é arte? 150 anos de arte moderna, do impressionismo ate' hoje. Traduzido por Maria Luiz Borges. Rio de Janeiro: Zahar, 2012.

HUBERT, Marie-Claude. As grandes teorias do teatro. Traduzido por Eduardo Brandão. São Paulo: Editora WMF Martins Fontes, 2013

JARRY, Alfred. «De l'inutilité du théâtre au théâtre», Mercure de France, septembre 1896. Reproduit dans Tout Ubu, Paris, Librairie générale française, «Le Livre de poche», nos838-839, 1962, p. 139-145.

KRYSINSKI. Wladimir. Dialéticas da transgressão: o novo e o moderno na literatura do século XX. Traduzido por Ignacio Antônio Neis, Michel Peterson e Ricardo Iuri Canko. São Paulo: Perspectiva, 2007. 
LEHMANN, Hans-Thies. Teatro pós-dramático e teatro político. In: GUINSBURG, J. FERNANDES, Sílvia (Org.). O pós-dramático. São Paulo: Perspectiva, 2009.

LEHMANN, Hans-Thies. Teatro pós-dramático. Traduzido por Pedro Süssekind. São Paulo: Cosac Naify, 2007.

PERLOFF, Marjorie. A escada de Wittgenstein: a linguagem poética e o estranhamento do cotidiano. Traduzido por Elisabeth Rocha Leite e Aurora Fornoni Bernardini. São Paulo: Edusp, 2008.

RYAN, Betsy Alayne. Gertrude Stein's theatre of the absolute. Ann Arbor: Umi, 2006.

STEIN, Gertrude. A autobiografia de Alice B. Toklas. Traduzido por José Rubens Siqueira. Porto Alegre: L\&PM, 2006.

STEIN, Gertrude. Last operas and plays. Nova Iorque: Vintage, 1975.

Recebido em 21/09/2017

Aceito em 22/12/2017 